\title{
Lunar Magnetism Orchestrates Menstrual Cycle in Symphony of Life
}

\author{
Venkata Subba Rao Yeragudipati \\ University Science and Instrumentation Centre, Sri Venkateswara University, Tirupati, India \\ Email address: \\ yvsubbarao2004@yahoo.com

\section{To cite this article:} \\ Venkata Subba Rao Yeragudipati. Lunar Magnetism Orchestrates Menstrual Cycle in Symphony of Life. American Journal of Biomedical \\ and Life Sciences. Vol. 7, No. 5, 2019, pp. 104-109. doi: 10.11648/j.ajbls.20190705.12
}

Received: July 26, 2019; Accepted: August 28, 2019; Published: October 9, 2019

\begin{abstract}
Female humans have an internal menstrual cycle rhythmicity that helps them anticipate and adapt to the regular rhythm of the Lunar Month and intensity of Moon Light. But how does this menstrual cycle rhythmicity work? This paper presents my discovery elucidating female menstrual cycle rhythmicity and its inner workings with Lunar cycle rhythmicity and Moon Light intensity. Moon plausibly controls the hypothalamus which is responsible for producing the hormone that triggers the start of female menstrual cycle. The five different hormones released from the hypothalamus have a different effect on the anterior pituitary gland, stimulating it to release or stop releasing a particular hormone in tune with the lunar phases of waxing and waning. The discovery explains how female humans' menstrual cycle adapt their physiology and biological rhythm so that it is synchronised with the Moon's rotations and its phases both of which holds a plausible relationship in duration of their phases and in the volume of intensity of moonlight due to waxing or waning with that of the thickening or dissolution of the endometrium besides the growth of one single large egg cell for fertilisation; and in the absence of fertilisation bring about dissolution. Thus, deciphering of female human menstrual cycle rhythmicity leading to the plausible pregnancy is a cosmic process due to combined effect of Interplanetary Magnetic Field (IMF) and Geomagnetic Field (GMF). This opens up whole new fields of research which helps in treating irregular monthly periods and infertility by a suitable magnetic therapy. The intensity of moonlight varies greatly depending on the current lunar phase. The phases of the moon are the result of the earth's shadow being cast on the surface of the moon. In short, the reflected light from the moon being also electromagnetic wave interacting with Geomagnetic Field modulates female menstrual rhythmicity cycle of all its phases and also helps in normalising monthly periods by exposure to natural light besides helps in finding suitable magnetic therapy for infertility.
\end{abstract}

Keywords: Phases of the Moon, Menstrual Cycle Phases, Hypothalamus, Hormones, Solar System, Interplanetary Magnetic Field, Geomagnetic Field, Zodiac, DNA, Panspermia

\section{Introduction}

Different scientific theories are abounding on the origins of life including the one, namely, Panspermia Theory, which is out of this world. This theory is gathering momentum of support from science with the advancement of space science and with new evidences of life building blocks being available as readymade kits in space. Majority of the Cosmologists support the view that the universe's structure is wholly electromagnetic. This concept indeed resonated with me for many years which inspired me to unravel the mechanism involved in Evolution of species including humans. Of all the four known forces in Physics, Electromagnetic force possibly plays a vital role Omnipresent throughout the universe, magnetism is known to affect the biological cycles of numerous creatures here on Earth, including humans. Inter Planetary Magnetic Field (IMF) telegraph signals of myriad frequencies to interact with the geomagnetic field and the Earth in turn telegraph these signals to the organism living on Earth via their neural network i.e., to the already pre-programmed DNA for evolution. Earth and its satellite, the Moon, also receive sunlight which is electromagnetic wave. Studies found a synchronous relationship between the menstrual cycles and lunar rhythm.

Female Menstruation is an important physiological process in the Reproduction System. Menstruation occurs on a monthly cycle throughout female reproductive life. A better understanding of the rhythmicity of phases of moon and its electromagnetic energy influences orchestrated by its revolution 
helps us, develop a better and more harmonious relationship with it and appreciate the rhythmicity of female human menstrual phases which are entirely in harmony with it in the symphony of life in her reproduction system heralding child birth. "It's called the lunar effect, and, as far as births are concerned, the primary explanation for the effect focuses on the moon's gravitational pull. It basically states that much the way the moon's gravity controls the tides, it can control a woman's body. The human body is 80 percent water, after all. This argument put forth here is based on single-link theory which are simple models which can be easily disproved. This approach ignores the possibility of multi-link theories. Gravity can't possibly work because of the weak tidal tug of the planets [1]. And, given that both menstruation and ovulation roughly follow a lunar cycle - occurring on a monthly basis -- it doesn't seem too far off to think that the moon could have a say in childbirth as well" [2]. An attempt is made here to establish the relationship between Phases of the Moon and the Phases of Menstrual Cycle.

"Life on Earth is adapted to the rotation of our planet. For many years' we have known that living organisms, including humans, have an internal, biological clock that helps them anticipate and adapt to the regular rhythm of the day. But how does this clock actually work? Jeffrey C. Hall, Michael Rosbash and Michael W. Young (all Nobel Laureates) were able to peek inside our biological clock and elucidate its inner workings. Their discoveries explain how plants, animals and humans adapt their biological rhythm so that it is synchronized with the Earth's revolutions. With exquisite precision, our inner clock adapts our physiology to the dramatically different phases of the day. The clock regulates critical functions such as behaviour, hormone levels, sleep, body temperature and metabolism".

In a similar way, effort has been put in the present study showing female human menstrual cycle is adapted to the regular rhythm of the lunar month. The inner clock adapts the female biological rhythm so that it is synchronized with the Moon's revolutions. With exquisite precision, female human inner clock adapts to their physiology to the dramatically different phases of the lunar month. The clock regulates hormone levels where Moon triggers hypothalamus.

\section{Menstrual Cycle}

A brief introduction to Zodiac is necessary for understanding the Phases of the Moon corresponding to the Phases of Menstrual Cycle in terms of their duration and size. The planets move round the Sun in a circular belt of space in the heavens. This elliptical belt is called the 'Zodiac'. The centre line of the Zodiac is known as ecliptic. The zodiac is $16^{0}$ in breadth with $8^{0}$ on either side of the ecliptic. This belt is comprehensive enough to accommodate the movements of all the planets and the Sun. Zodiac is also called the 'Milky Way'. Zodiac is the apparent path of the Sun viewed from the centre of the Earth. For convenience, the zodiac $360^{\circ}$ is equal to 29 days signifying one Lunar Month. The moon cycle has 29.5 days, changing from the waxing new moon of increasing light, to the full moon of total illumination, to the dark waning moon of decreasing light, and back to the waxing new moon of increasing light again. The Lunar Month is divided into 4 significant segments, namely, (a) New Moon to $1^{\text {st }}$ Waxing Crescent (Day 1 to 5), (b) New Moon to end of Waxing Gibbous (Day 1 to 14), (c) Full Moon (Day 15), and (d) beginning of Waning Gibbous to New Moon (Day 16-29) (Figure 1).

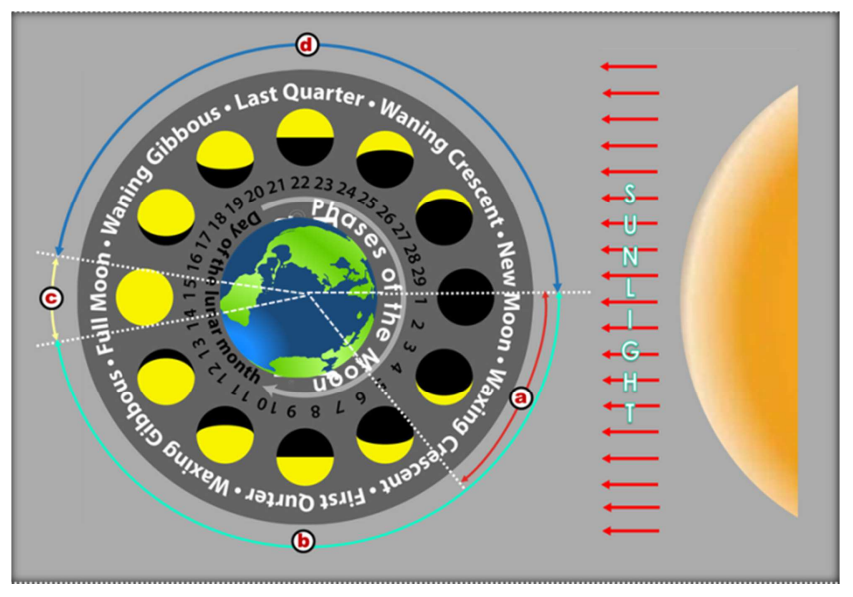

Figure 1. Phases of Moon as it transits in the zodiac in one Lunar Month.

Month after month, the moon cycle mirrors a woman's menstrual cycle, which coincidentally has an average length of 29.5 days as well. Similar to the moon cycle, a woman's menstrual cycle changes from the menstruation of new growth, to the ovulation of full power and blossom, to the pre-menstrual phase of harvest and degeneration, and back to menstruation of renewal again. Women experience the monthly menstrual bleeding or the menstrual cycle or the menstrual period from early teen until menopause. Menstruation occurs on a monthly cycle throughout female reproductive life. Women's menstrual cycles begin more often during a New Moon. Studies found a synchronous relationship between the menstrual cycles and lunar rhythm. Among 826 females with a normal menstrual cycle, aged between 16 and 25 years, more than 28 percent of all menstruations occurred around the New Moon. The proportion of menstruations at other times during the lunar month ranged between 8.5 and 12.6 percent [3].

Pregnant women spontaneously deliver more often during a Full Moon. The study that examined all full-term spontaneous deliveries (without mechanical or drug intervention) at the Civil Hospital, Fano) during a two-year period found a significant relationship in women who had one or more previous pregnancies and their deliveries clustered around the Full Moon [4]. Other research analysis conducted a) During 1996, Joshi et al examined the relationship between the lunar position and spontaneous deliveries, especially in relation to the presence of a full moon [5]. b) A retrospective analysis of 1248 spontaneous full-term deliveries in a three-year period (36 lunar months) was done at the Department of Obstetrics and Gynaecology, Civil Hospital, Fanon (Marche, Italy). Both these studies 
showed a connection between spontaneous full-term deliveries and the lunar month. The Moon has synchronous rotation with the Earth; it's rotation period is the same as that of the Earth. On a New Moon Day, Moon is at $0^{0}$ elongation to the Sun while on a Full Moon Day, Moon is at $180^{\circ}$ Elongation to the Sun with reference to Earth (Figure 2).
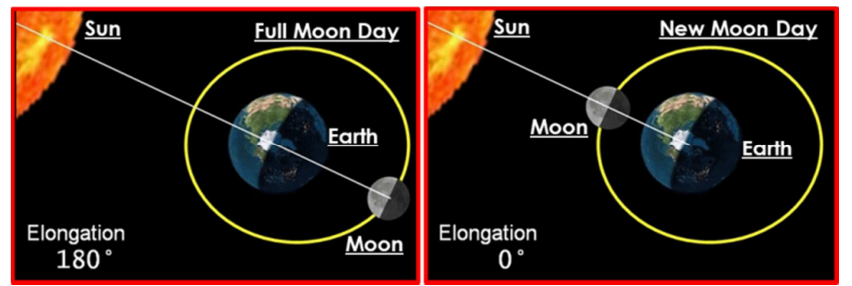

Figure 2. Positions of Sun, Earth and Moon on a New Moon and a Full Moon Day as Moon transits in the Zodiac in one Lunar Month.

\section{Variable Menstrual Periods: Natural Cure}

Usually, the regular menstrual period lasts a lunar month of 29 days. Not all women do have regular periods. Regular monthly period in females is plausibly affected due to changes in life styles resulting in any mismatch between the internal biological menstrual cycle and the regular lunar rhythmicity and Moon Light intensity. It is a common notion that the natural cycle of women who live and sleep out in the open away from artificial light is to ovulate on the full moon and menstruate on the new moon. But this may not be the case for most modern women whose natural rhythms are largely affected by artificial light. Some women may menstruate on the new moon, some on the crescent moon, some on the full moon, some on the waning moon, and others on the new moon. Before electricity and the light bulb were invented, shifts in the amount of light intensity at night during the moon's various phases could possibly have played a significant role in our menstrual cycle of Moon by affecting certain body processes impacted by light exposure, such as the production of the hormone, thus prompting tying a relationship of female menstrual cycle to the moon cycle.

An interesting 1990 study in the journal Psychiatry Research found that bright light at night can help regulate the menstrual cycle. In the study, women with abnormally long cycles of about 45 days who slept with a 100 -watt bulb turned on at night in their bedroom from Day 13 to Day 17 of their cycle successfully shortened their cycles to about 33 days. Light is the reflected Sunlight and the Sunlight itself is an electromagnetic wave of light and particles. This is the correct view of the matter is evidenced by the fact that Women with variable onset of menstrual periods, artificial illumination of the bedroom through the 14th to 17 th nights following the onset of menstruation resulted in the regularization of the period [6].

\section{Phases of Menstrual Cycle}

Series of changes take place every month wherein the uterus expands a new lining for receiving fertilised egg. When no fertilised egg is present to initiate pregnancy, the uterus discards its lining. The menstrual cycle or the menstrual period is counted from Day 1 of bleeding and ranges until the next phase, which usually is one lunar month of about 29 days [7]. The whole duration of one lunar month of 29 days of a menstrual cycle is segmented into the following four prominent phases and correspond to the following four prominent phases of the Moon (Figure 3).

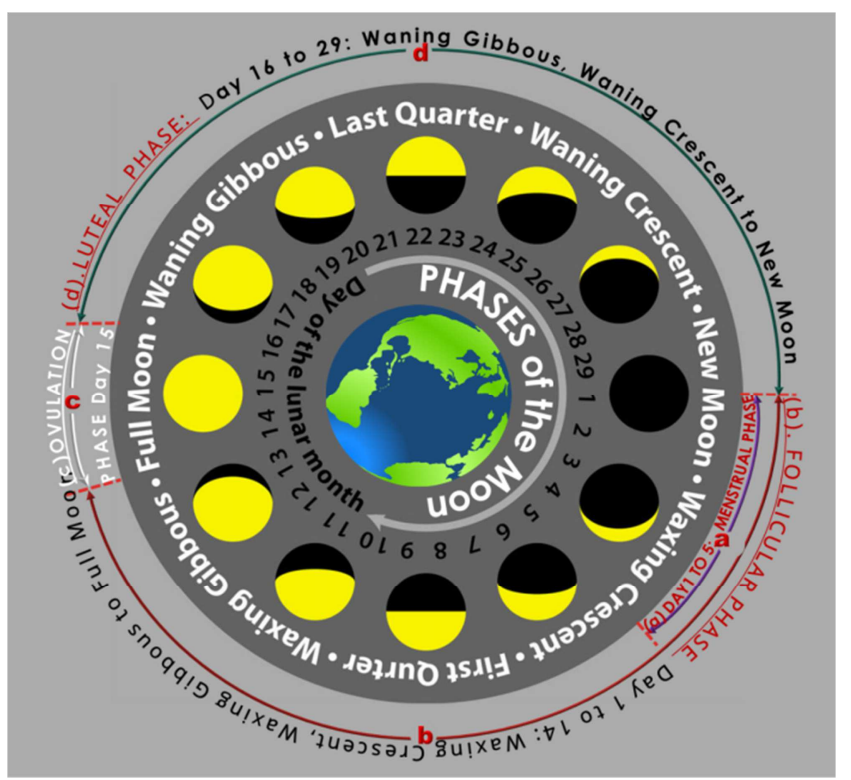

Figure 3. Phases of the Moon as it transits in the Zodiac in one Lunar Month and the corresponding Phases of Menstrual Cycle.

From Day 1 to 5: Menstrual Phase: New Moon to $1^{\text {st }}$ Waxing Crescent: From Day 1 to Day 14: Follicular phase: New Moon to end of Waxing Gibbous Day 15: Ovulation phase: Full Moon

From day 16 to 29: Luteal phase: beginning of Waning Gibbous to New Moon.

\subsection{Menstrual Phase from Day 1 to Day 5}

Menstrual phase begins on the first day of menstruation and lasts till the 5th day of the menstrual cycle. The Moon traverses the Zodiac from Day 1 to Day 5 by being in elongation of $\mathrm{E} 60^{\circ}$ to the Sun from its place of New Moon shows the first waxing crescent on the night of Day 5, after four dark nights, correspond to Menstrual Phase during which the uterus sheds its inner lining of soft tissue and blood vessels which exits the body in the form of menstrual fluid of black/brown colour.

\subsection{Follicular Phase from Day 1 to Day 14}

Moon traversing from New Moon to Full Moon and being in elongation of $180^{\circ}$ to the Sun, waxing all through becomes full bright circle corresponds to the growth of the egg cells in the ovaries of which one of these egg cells fully mature while uterus develops a lining of blood vessels and soft tissue called endometrium and the whole endometrium becomes thicker corresponding to the waxing Moon to becoming Full Moon on day 15. 


\subsection{Ovulation Phase Day 15}

Ovulation is when a human female is fertile. She can only conceive during this time, which usually occurs around day 14 of her cycle. Female humans, unlike any other species, however, can be sexually active at any time. Alas! with this great freedom comes great responsibility especially for the two most populous countries, China and India, where a little more than one-third of world's population live. The ovary releases the matured egg cell caused by a hormone secreted by the pituitary gland. The egg cell thus released during the ovulation phase stays for 24 hours' duration ready to be impregnated by the sperm cell. The union of an ovum (egg cell) and a sperm cell called fertilisation results in a zygote. The whole process corresponds to 24 hours of stay of Full Moon Day.

\subsection{Luteal Phase Day 16 to 29}

This phase begins on the 16th day and lasts till the end of the cycle $29^{\text {th }}$ day. If the egg cell, released during the ovulation phase after staying in the fallopian tube for 24 hours, is not impregnated by the sperm cell, the egg cell disintegrates. The hormone that causes the uterus to retain its endometrium gets used up by the end of the menstrual cycle. This causes the menstrual phase of the next cycle to begin at New Moon and this corresponds to beginning of waning of the Moon during dark fortnight.

\section{Correlation Between Human Female Menstrual Phases of the Menstrual Cycle and Phases of the Moon}

Human Female Menstrual Cycle exhibits a close relationship with the Phases of the Moon during Lunar Month of 29 Days in terms of their duration as well as their functions. This relationship is correlated and presented as follows for brevity (Table 1). Specific moon phase energies, when they magnify phases of menstrual cycle, can be freed up and made available for use if we choose to work with them.

Table 1. Correlation of Human Female Menstrual Phases and Phases of the Moon of their duration as well as their functions.

\begin{tabular}{|c|c|c|c|c|}
\hline $\begin{array}{l}\text { Sl. } \\
\text { No. }\end{array}$ & $\begin{array}{l}\text { Phases of Human } \\
\text { Female Menstrual } \\
\text { Cycle }\end{array}$ & $\begin{array}{l}\text { Relation Phases of Moon } \\
\text { to Phases of Menstrual } \\
\text { Cycle }\end{array}$ & $\begin{array}{l}\text { Duration of Phases in } \\
\text { Both the cases }\end{array}$ & $\begin{array}{l}\text { Comparison of Nature of Function and Duration of Phases in } \\
\text { Both the cases }\end{array}$ \\
\hline 1 & Menstrual Phase & $\begin{array}{l}\text { Beginning of New Moon to } \\
\text { First Ascent }\end{array}$ & Day 1 to day 5 & $\begin{array}{l}\text { Discharge of black/brown blood similar } 5 \text { dark nights the uterus } \\
\text { sheds the lining (endometrium) built up in the previous } \\
\text { menstrual cycle as the Moon sheds its darkness. Hormones are at } \\
\text { their lowest. }\end{array}$ \\
\hline 2 & Follicular Phase & $\begin{array}{l}\text { New Moon to Full Moon } \\
\text { (Waxing Moon) }\end{array}$ & Day 1 to day 14 & $\begin{array}{l}\text { Uterine lining (endometrium) is regrown like the waxing moon. } \\
\text { Oestrogen levels increase during } 14 \text { days from New Moon. } \\
\text { Different levels of hormones are released and release of fully }\end{array}$ \\
\hline 3 & Ovulation Phase & New Moon & Day 15 & $\begin{array}{l}\text { developed egg like the Full Moon in shape and size. Oestrogen } \\
\text { levels peak at the Full Moon on the } 15^{\text {th }} \text { day. }\end{array}$ \\
\hline 4 & Luteal Phase & $\begin{array}{l}\text { End of Full Moon to } \\
\text { beginning of New Moon } \\
\text { (Waning Moon) }\end{array}$ & Day 16 to day 29 & $\begin{array}{l}\text { If the egg is not fertilised then the menstrual cycle continues for } \\
\text { another 14-15 days from day } 16 \text { to day } 29 . \text { Decline in release of } \\
\text { levels of hormones and endometrium begin to die and shed. }\end{array}$ \\
\hline
\end{tabular}

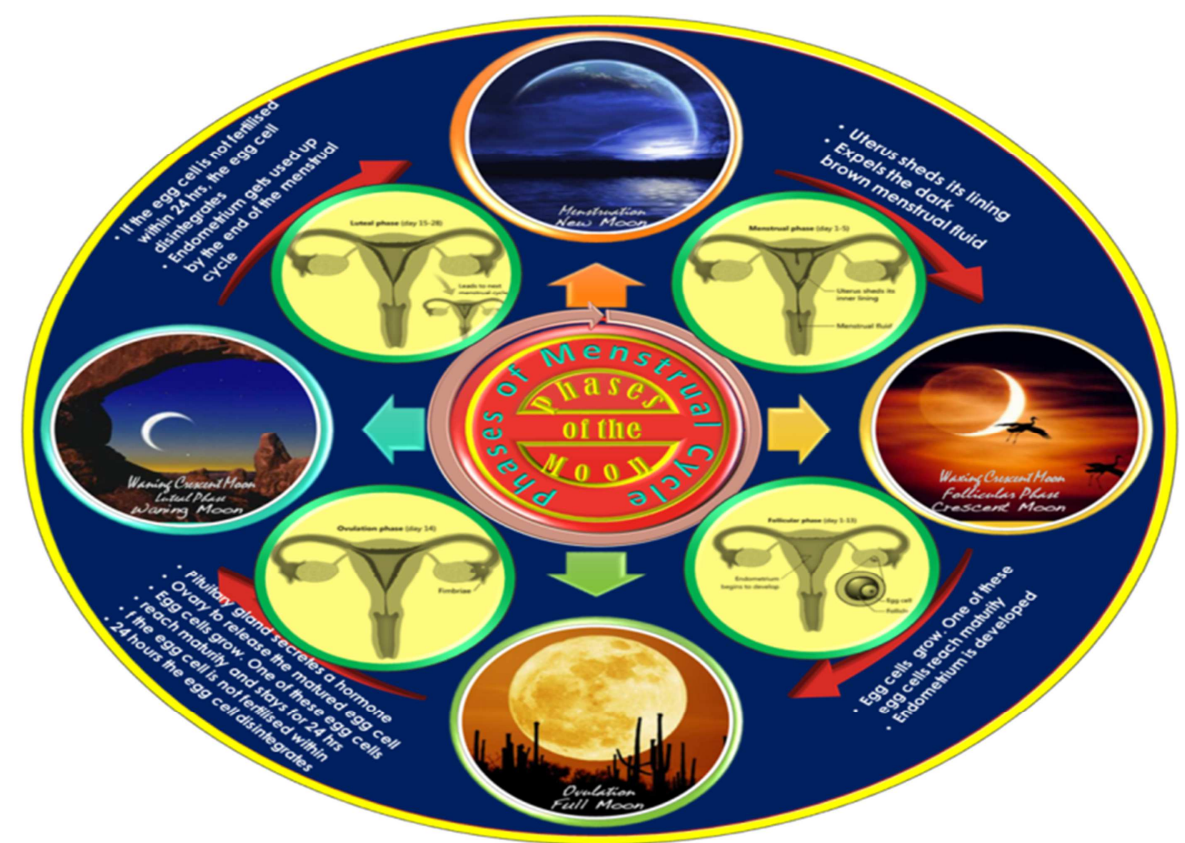

Figure 4. Correlation of Phases of the Moon and Phases of Female Menstrual Cycle of Functions and Durations. 


\section{Child Birth}

If the egg relead during ovulation is fertilised, the zygote (tiny fertilized egg) will latch onto the lining and the woman becomes pregnant, the uterine lining (endometrium) stays in place and nourishes the fertilised egg. The lining then becomes the placenta which holds and protects the egg. As the foetus develops, the placenta eventually takes on the task of supporting the lining of the uterus to maintain the pregnancy. Normally, periods stop during pregnancy. During pregnancy, periods stop because of change in hormones that prevent ovulation. There is no ovulation and no need for shedding the lining of uterus.

The foetus's neural network acts as a sort of antenna that tunes into fluctuations in Earth's magnetic field ipso facto moon'. Earth's magnetosphere can affect the developing foetus. Throughout the entire nine-month gestation period, the neural network of the foetus may be synchronizing and tuning its biological clock into Earth's magnetic fluctuations, ipso fact the Moon. Earth's magnetosphere contains a wide range of frequencies, one of which is known to be connected to the Moon. Thus, our own resonances to these preprogramed magnetic signals may be evolving along with changes in Earth's magnetic field [7].

\section{Conclusions}

Of all the four known forces of Physics, namely, Electromagnetism, Gravity, Strong Nuclear Energy and Weak Nuclear Energy, only electromagnetism works in the origin and evolution of all species including humans. Gravity does not work because of the weak tidal tug of the planets.

The solar system is an intricate web of planetary fields and resonances. Omnipresent throughout the universe, magnetism is known to affect the biological cycles of numerous creatures here on Earth, including humans.

Earth's magnetosphere contains a wide range of frequencies. Those frequencies in Earth's magnetosphere that are close to the tidal frequencies of the planets Venus, Mars, Jupiter, and Saturn will remain in step with those planets. One such frequency is associated with the Moon - the lunar daily magnetic variation.

The Sun, Moon, and planets telegraph their effects to us via magnetic signals. These planetary magnetic signals are then perceived by the neural network of the foetus inside the mother's womb, heralding the child's birth.

Female Menstruation is an important physiological process in the Reproduction System. Menstruation occurs on a monthly cycle throughout female reproductive life. There are five different hormones released from the hypothalamus that have an effect on the menstrual cycle. Each of these have a different effect on the anterior pituitary gland, stimulating it to release or stop releasing a particular hormone.

Moon's Phases are connected to the Earth's revolution. Hypothalamus is responsible for producing the hormone that triggers the start of your menstrual cycle. Moon, appears to control hypothalamus, as its phases are similar to the Phases of Menstruation Cycle in relation to their duration and similarities in growth and death of uterine wall (endometrium) to waxing and waning Moon. French statistician and scientist Michel Gauquelin's work, in which human biological clocks keep time with the planets.

Pregnant Women Spontaneously Deliver More Often During a Full Moon: The Italian Journal, Minerva Ginecol, published a study [March 1997; 49 (3): 91-94] that examined all full-term spontaneous deliveries (without mechanical or drug intervention) at the Civil Hospital in Fano during a twoyear period. A significant relationship was found in multigravida women (females who had one or more previous pregnancies): their deliveries clustered around the full moon.

Women's Menstrual Cycles Begin More Often During a New Moon: The Scandinavian Journal, Acta Obstet Gynecol Scand. published a study [1986; 65 (1): 45-48] that found "a synchronous relationship between the menstrual cycle and lunar rhythm." Among 826 females with a normal menstrual cycle, aged between 16 and 25 years, more than 28 percent of all menstruations occurred around the new moon. (The proportion of menstruations at other times during the lunar month ranged between 8.5 and 12.6 percent.)

Specific moon phase energies, when they magnify phases of menstrual cycle, can be freed up and made available for use if we choose to work with them.

The foetus's neural network acts as a sort of antenna that tunes into fluctuations in Earth's magnetic field. Earth's magnetosphere can affect the developing foetus. Throughout the entire nine-month gestation period, the neural network of the foetus may be synchronizing and tuning its biological clock into Earth's magnetic fluctuations, ipso fact the Moon. Thus, our own resonances to these preprogramed magnetic signals may be evolving along with changes in Earth's magnetic field.

\section{Acknowledgements}

I profusely thank my son, Prof. Y. V. Ramana Rao, M. Tech., Ph. D., for his critical and constructive comments.

\section{Dedication}

This work is dedicated in loving memory of my wife whose loving spirit sustains me still.

\section{References}

[1] Allen Kevin, 2007, The Reluctant Hypothesis (A History of Discourse Surrounding the Lunar Phase Method of Regulating Conception), Lacuna Press, ISBN 978-0-9510974.

[2] Callahan, (Aug 9, 2011), DNA Blocks found in Meteorites, Proceedings of the National Academy of Sciences of the United States of America.

[3] Cann, Rebecca L., Stoneking, Mark, Wilson, Allan C, (1987) Mitochondria DNA and human evolution, publ: Nature, Vol. 325. 
[4] Encyclopaedia Britannica (1994; Macropaedia article on Animal Behaviour, p. 761).

[5] Frank Brown, post 56782, html\#, a summary Brown's work.

[6] https://www.tandfonline.com> eprint> fullJan 15, 2018 eferences... The term "circadian rhythm" refers to the daily cycles that almost all biological... A later study by Michael W. Young indicated that not only does the... working on this research, Michael Rosbash and Jeffrey C. Hall were...... Discoveries of molecular mechanisms controlling the circadian rhythm.

[7] https://menstrupedia.com/articles/physiology/cycle-phases.

[8] Joshi R, Bharadwaj A, Gallousis S, Matthews R. Labor ward workload waxes and wanes with the lunar cycle, myth or reality? Primary Care Update Ob Gyns. 1998 Jul 1; 5 (4): 184. 6.

[9] Journal of Astrobiology (ANI), 2012, European Planetary Congress, Washington.

[10] Michel Gauquelin, The Cosmic Clocks, San Diego, CA: ACS Publications, 1982. Text.

[11] The Italian Journal, Minerva Ginecol., [March 1997; 49 (3): 91-94].

[12] The Scandinavian Journal, Acta Obstet Gynecol Scand, 1986; 65 (1): $45-48$

[13] Percy Seymour, (1997) The Scientific Basis of Astrology, W. Foulsham, Slough, U. K.: Quantum.

[14] Rao, Y. V. S, (Nov 2014), Natal Charts vis-a-vis DNA Entries Journal of Advances in Philosophy Online Journal www.cirworld.com, Vol. No.1, Page 14-19.

[15] Rao, Y. V. S, (2015), Moon-Mars Magnetism in Female
Menstrual Cycle, Journal of Advances in Philosophy Vol. 1, No. 1, 2015.

[16] Rao, Y. V. S (2015), "Vedic Astrology (Vedānga) Reintegrated into Astronomy, Astrophysics and Astrobiology" (2015) Publisher: Sri Venkateswara Vedic University, Tirupati, ISBN 978-93-81887-74-5<< Text.

[17] Rao, Y. V. S, (2017), "Magus of Astromagnetism", by Yeragudipati Venkata Subba Rao, Publisher: Lambert Academic Publiations (LAP) West Germany, ISBN 978-3330-32022-2 $<<$ Text

[18] Seymour P (1990). Astrology: The Evidence of Science. Revised edition, Arkana, London. 248 pages.

\section{Biography}

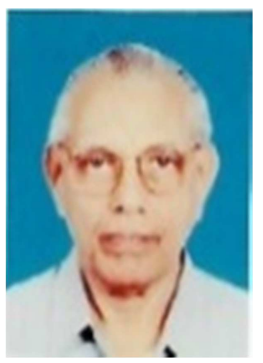

Venkata Subba Rao Yeragudipati, Ph.D., FIE., C. Eng. (I) was born in 1938. He is a Chartered Mining Engineer, Govt. of India Certified Mines Manager, Certified Mines Surveyor, Astronomer, Author and Astrologer. $\mathrm{He}$ was a faculty member of Mining Engineering Department of Osmania University, Hyderabad and later in Geology Department of S. V. University, Tirupati, India. After retirement, as Executive Engineer, he served as Visiting Professor of Jyotish (Astronomy), Rāshtriya Sanskrit Vidyāpeeth (University), Tirupati (2000-2013). He is the author of several books on Veda-Sciences and has several research papers to his credit. He is a Member of several professional bodies. 